\title{
Use of the train-of-five bipolar technique to provide reliable, spatially accurate motor cortex identification in asleep patients
}

\author{
Evan D. Bander, MD, ${ }^{1}$ Evgeny Shelkov, BSN, ${ }^{2}$ Oleg Modik, PhD, ${ }^{2}$ Padmaja Kandula, MD, ${ }^{2}$ \\ Steven C. Karceski, MD, ${ }^{2}$ and Rohan Ramakrishna, MD1 \\ Departments of ${ }^{1}$ Neurosurgery and ${ }^{2}$ Neurology, NewYork-Presbyterian/Weill Cornell Medicine, New York, New York
}

\begin{abstract}
OBJECTIVE Intraoperative cortical and subcortical mapping techniques have become integral for achieving a maximal safe resection of tumors that are in or near regions of eloquent brain. The recent literature has demonstrated successful motor/language mapping with lower rates of stimulation-induced seizures when using monopolar high-frequency stimulation compared to traditional low-frequency bipolar stimulation mapping. However, monopolar stimulation carries with it disadvantages that include more radiant spread of electrical stimulation and a theoretically higher potential for tissue damage. The authors report on the successful use of bipolar stimulation with a high-frequency train-of-five (TOF) pulse physiology for motor mapping.
\end{abstract}

METHODS Between 2018 and 2019, 13 patients underwent motor mapping with phase-reversal and both low-frequency and high-frequency bipolar stimulation. A retrospective chart review was conducted to determine the success rate of motor mapping and to acquire intraoperative details.

RESULTS Thirteen patients underwent both high- and low-frequency bipolar motor mapping to aid in tumor resection. Of the lesions treated, $69 \%$ were gliomas, and the remainder were metastases. The motor cortex was identified at a significantly greater rate when using high-frequency TOF bipolar stimulation $(n=13)$ compared to the low-frequency bipolar stimulation $(n=4)(100 \%$ vs $31 \%$, respectively; $p=0.0005)$. Intraoperative seizures and afterdischarges occurred only in the group of patients who underwent low-frequency bipolar stimulation, and none occurred in the TOF group (31\% vs $0 \%$, respectively; $p=0.09$ ).

CONCLUSIONS Using a bipolar wand with high-frequency TOF stimulation, the authors achieved a significantly higher rate of successful motor mapping and a low rate of intraoperative seizure compared to traditional low-frequency bipolar stimulation. This preliminary study suggests that high-frequency TOF stimulation provides a reliable additional tool for motor cortex identification in asleep patients.

https://thejns.org/doi/abs/10.3171/2019.11.FOCUS19776

KEYWORDS intraoperative motor mapping; bipolar; train-of-five; seizure; stimulation

$\mathrm{I}$ NCREASING evidence highlights the importance of gross-total or maximal resection in improving survival in patients with glioblastoma. ${ }^{16,17,20,28,33} \mathrm{~A}$ number of techniques ranging from functional MRI and diffusion tensor imaging to transcranial magnetic stimulation have become popular in helping to identify the border of tumor and its relationship to regions of eloquent cortex..$^{9,12,40} \mathrm{An}$ other primary tool in this repertoire is direct cortical and subcortical stimulation. ${ }^{5,11,27}$ Evidence has shown that there is considerable patient-to-patient variability with regard to eloquent cortex. ${ }^{1,3}$ In the presence of a mass lesion, there is also distortion/reorganization of anatomical pathways.?
For these reasons, cortical and subcortical mapping techniques have become fundamental during tumor resection to minimize damage to eloquent tissue. . $, 8,13,19,23,27,32$

Traditional bipolar stimulation is low-frequency (40-60 $\mathrm{Hz}$ ) and uses a biphasic or balanced charge. This means that the stimulation at each electrode switches polarity halfway through to prevent leaving a net charge at the site of stimulation. When compared to monopolar stimulation, bipolar stimulation has been shown to cause less damage to tissue in animal models. . $^{10,18,22}$ However, a known complication of cortical bipolar stimulation is intraoperative seizures. ${ }^{19,25,30,34,39}$ Not only can intraoperative seizures 

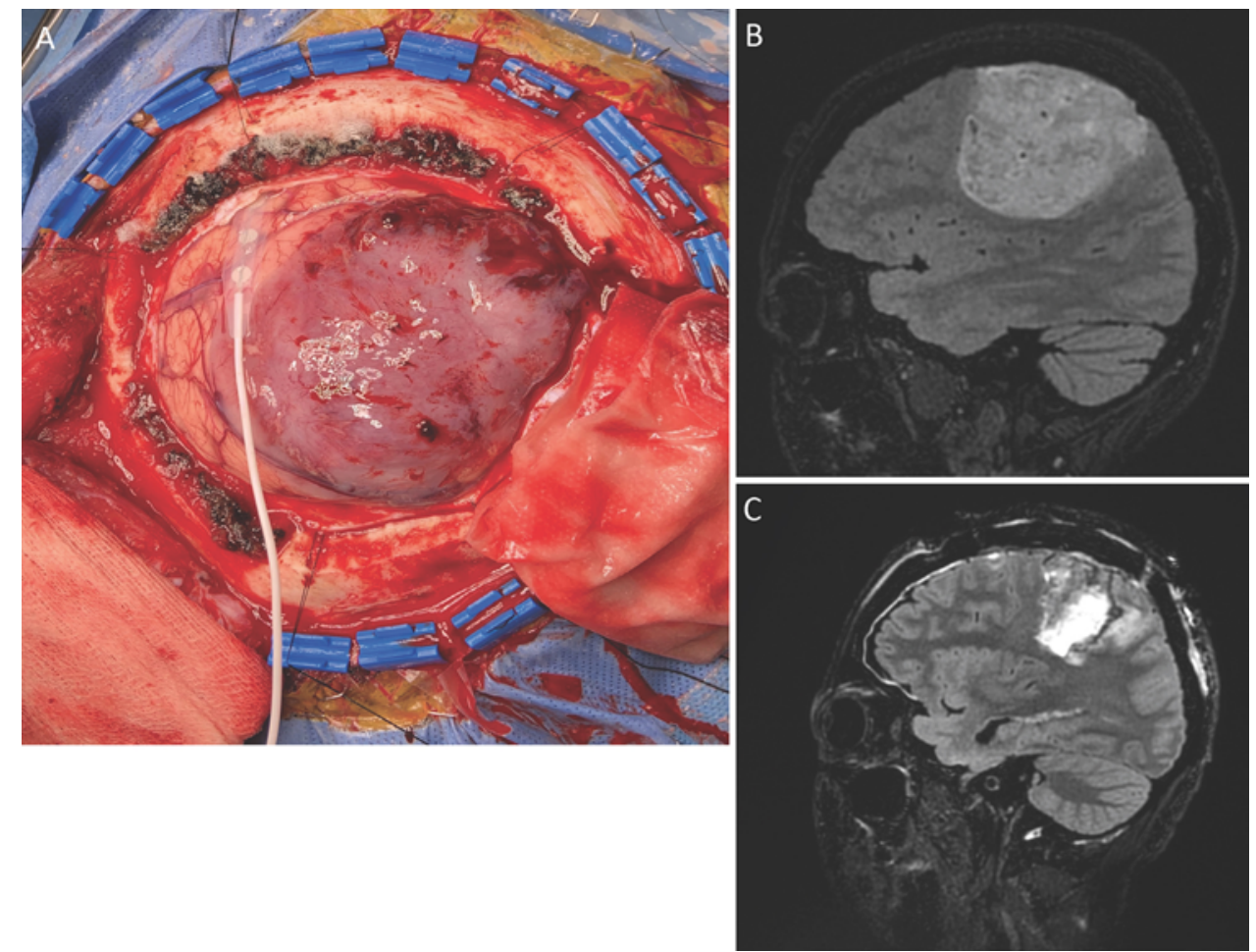

FIG. 1. A: Intraoperative photograph showing a tumor involving the posterior portion of the somatosensory cortex. B and C: Preoperative and postoperative T2-weighted sagittal FLAIR MR images of the corresponding tumor.

cause injury and require prompt treatment with application of ice-cold saline and/or rapid administration of benzodiazepines or antiepileptics, but they can also preclude further functional mapping. ${ }^{29}$ Moreover, bipolar stimulation may fail to identify the motor cortex in a diseased brain. ${ }^{35}$ The use of monopolar high-frequency (250-500 $\mathrm{Hz}$ ), train-of-five (TOF) stimulation has recently been shown to deliver reliable motor and language mapping while causing decreased seizure activity. ${ }^{24,35,37}$ The main theoretical disadvantage to monopolar TOF stimulation is diffuse, radial spread of electrical stimulation that leads to spatially inaccurate motor cortex identification.

We provide a third possibility, one that combines the two: anodal TOF stimulation delivered between two electrodes. This can be done using a traditional bipolar wand or using two electrodes of a subdural strip that is placed in the surgical field, immediately adjacent to the area of resection. With this technique, we hope to deliver highly reliable TOF stimulation but in a more focused way akin to low-frequency bipolar stimulation. This case series contrasts the use of high-frequency bipolar TOF stimulation with low-frequency bipolar cortical stimulation during intraoperative mapping. Two variables were of primary interest: 1) the ability to map the motor cortex and 2) the occurrence of intraoperative seizures.

\section{Methods}

This study was approved by the Institutional Review Board at Weill Cornell Medical College. A retrospective chart review was completed to identify demographic data, pathology, intraoperative stimulation data, preoperative and intraoperative seizure status, and postoperative surgical complications. Between 2018 and 2019, 13 patients underwent motor mapping with phase-reversal and both low- and high-frequency bipolar stimulation.

\section{Intraoperative Monitoring Techniques}

Standard neurosurgical approaches, including the use of intraoperative neuronavigation and ultrasound, were used to identify the tumor location and to perform a craniotomy appropriately tailored for the resection. A Cascade Elite machine (Cadwell) was used for all neuromonitoring modalities.

Once the dura mater was open, several intraoperative modalities were employed. First, median nerve stimulation "phase reversal" was accomplished using a 6- or 8-contact subdural electrode (Ad-Tech Medical; 10-mm contact spacing), placed perpendicular to the central sulcus. When present, the phase reversal confirmed the location of the central sulcus, thereby identifying the gross anatomical location of the motor cortex with respect to the tumor (Fig. 1). Subsequently, direct cortical stimulation motor mapping was performed in two ways (Table 1). First, high-frequency TOF bipolar stimulation was delivered using a TCS-4 stimulator (Cadwell) and a handheld neural probe (Double Ball Tip Probe, Cadwell). Needle recording electrodes monitored the motor response. The intensity of the stimulation was increased systematically until a motor evoked potential (MEP) was elicited, establishing a threshold for the MEP response. The subdural strip of electrodes was used to monitor afterdischarges or 
TABLE 1. Stimulation parameters

\begin{tabular}{lll}
\hline \multicolumn{1}{c}{ Parameter } & \multicolumn{1}{c}{$\begin{array}{c}\text { Low-Frequency } \\
\text { Stimulation }\end{array}$} & $\begin{array}{c}\text { High-Frequency } \\
\text { Stimulation }\end{array}$ \\
\hline Pulse & $\begin{array}{c}\text { Biphasic, rectangular, } \\
50 \mathrm{~Hz}\end{array}$ & TOF pulses \\
\hline Pulse width & $0.5 \mathrm{msec}$ & $0.05-0.075 \mathrm{msec}$ \\
\hline Intensity & $2-4 \mathrm{~mA}$ (peak to peak) & $10-100 \mathrm{~V}$ \\
\hline Polarity & Bipolar & Anodal \\
\hline $\begin{array}{c}\text { Stimulation duration/ } \\
\text { interstimulus interval }\end{array}$ & $1-6 \mathrm{sec} / \mathrm{NA}$ & $\mathrm{NA} / 3 \mathrm{msec}$ \\
\hline
\end{tabular}

$\mathrm{NA}=$ not applicable.

evoked intraoperative seizures. Following this, using the same handheld neural stimulator probe, low-frequency $(50-\mathrm{Hz})$ bipolar simulation was applied with a Nicolet Cortical Stimulator (Natus Neuro). A motor response was documented by clinical observations (observable muscle movements) and by recording a motor response in the needle recording electrodes.

After confirmation of the motor cortex location, attention was turned to the resection. During the resection, subthreshold direct cortical MEP responses were elicited every $2-15$ seconds, using the subdural electrode strip. In this way, MEP responses could be monitored throughout the resection. Electrophysiology monitoring was completed by a specialty-trained neurologist and staff.

\section{Statistical Analysis}

Two-sample proportion Fisher's exact test was used to calculate probability values for categorical variables, including the rate of positive motor mapping and intraoperative seizure frequency. A p value $<0.05$ was considered statistically significant. Microsoft Excel (Microsoft Corp.) and GraphPad Prism (GraphPad Software) were used for statistical analysis.

\section{Results}

A total of 13 patients (6 men and 7 women) underwent both high- and low-frequency bipolar motor mapping (Table 2). The mean patient age was 51 years (range 26-79 years). The majority of patients (69\%) had gliomas, and the remainder had metastatic tumors. Seizure was the most common presenting symptom in this cohort. The mean follow-up duration was 165 days (range 5-541 days). Table 2 demonstrates the demographics of the cohort.

The motor cortex was identified at a significantly greater rate when using the high-frequency TOF bipolar stimulator $(n=13)$ compared to the low-frequency bipolar stimulator $(n=4)(100 \%$ vs $31 \%$, respectively; $p=0.0005)$ (Table 3). The mean maximum stimulation intensity for the low-frequency stimulation was $8 \pm 2.2 \mathrm{~mA}$ (range 4-12 mA) and that for high-frequency TOF stimulation was $53 \pm 17.7 \mathrm{~V}$ (range 40-100 V). Low-frequency stimulation was successful at eliciting an MEP in $44 \%$ of the patients with gliomas $(n=4)$ but in $0 \%$ of the patients with metastatic tumors $(p=0.22)$. All patients underwent continuous MEP monitoring throughout the procedure
TABLE 2. Patient demographics

\begin{tabular}{|c|c|c|}
\hline Characteristic & Value & $\%$ \\
\hline Mean age, yrs & $51 \pm 15.9$ & \\
\hline Total no. of patients & 13 & \\
\hline Male & 6 & 46.2 \\
\hline Female & 7 & 53.8 \\
\hline \multicolumn{3}{|l|}{ Pathology } \\
\hline Glioblastoma & 6 & 46.2 \\
\hline Low-grade glioma & 3 & 23.1 \\
\hline Metastasis & 4 & 30.8 \\
\hline \multicolumn{3}{|l|}{ Surgical side } \\
\hline Right & 8 & 61.5 \\
\hline Left & 5 & 38.5 \\
\hline \multicolumn{3}{|l|}{ Tumor location } \\
\hline Frontal & 7 & 53.8 \\
\hline Parietal & 6 & 46.2 \\
\hline \multicolumn{3}{|l|}{ Presenting symptom } \\
\hline Asymptomatic & 2 & 15.4 \\
\hline Numbness/tingling & 3 & 23.1 \\
\hline Seizure & 5 & 38.5 \\
\hline Weakness & 3 & 23.1 \\
\hline Preoperative seizures & 7 & 53.8 \\
\hline Preoperative motor deficit & 5 & 38.5 \\
\hline Mean follow-up, days (range) & $165(5-541)$ & \\
\hline
\end{tabular}

Values are expressed as the number and percentage of patients unless otherwise indicated.

without intraoperative decrement. Five patients (38\%) had postoperative deficits, including supplementary motor area syndrome $(n=3)$, neglect $(n=1)$, or new postoperative weakness $(n=1)$. There were no ischemic strokes. Of the 5 patients with postoperative deficits, 2 had successfully elicited MEPs with both high- and low-frequency stimulation prior to resection. All of the postoperative deficits were improved at subsequent follow-up visits.

Intraoperative seizures $(n=2)$ occurred only in the lowfrequency bipolar group, and no seizures occurred in the TOF group, but this did not reach statistical significance $(15 \%$ vs $0 \%$, respectively; $p=0.48)$. Afterdischarges were identified in 2 patients in the low-frequency group, which, when combined with intraoperative seizures, trended toward a significantly higher rate in the low-frequency compared to high-frequency group $(\mathrm{p}=0.096)$. Both patients

TABLE 3. Operative outcomes

\begin{tabular}{lcc}
\hline \multicolumn{1}{c}{ Characteristic } & $\begin{array}{c}\text { Low-Frequency } \\
\text { Bipolar Stimulation }\end{array}$ & $\begin{array}{c}\text { TOF Bipolar } \\
\text { Stimulation }\end{array}$ \\
\hline Positive MEP & $4(30.8 \%)$ & $13(100 \%)^{*}$ \\
\hline Intraoperative seizure & $2(15.4 \%)$ & $0(0 \%)$ \\
\hline Mean max stimulation & $8 \pm 2.2 \mathrm{~mA}$ & $53 \pm 17.7 \mathrm{~V}$ \\
\hline Postoperative deficit & \multicolumn{2}{c}{$5(38 \%)$} \\
\hline
\end{tabular}

* Two-sample proportional Fisher exact method, $p<0.05$. 
who experienced intraoperative seizures had a history of preoperative seizures.

\section{Discussion}

Motor mapping has become an integral part of safe and maximal tumor resections. The origin of motor mapping can be traced primarily to the work of Wilder Penfield in the 1930s. Using 60-Hz stimulation over 1- to 6-second impulses, Penfield was able to elicit movements, sensations, or language interruption in patients. ${ }^{21,38}$ This form of stimulation, however, resulted in significant afterdischarges and seizures. The technique was advanced when Berger, Yingling, and Ojemann demonstrated that significantly lower stimulation intensities could elicit changes in monitored electromyography activity. ${ }^{38,39}$ The traditional bipolar method for motor and language mapping can limit motor deficits by halting resection at a minimum of $1 \mathrm{~cm}$ from positive stimulation points. ${ }^{11}$ The main drawback of this technique has been a concern for a high rate of intraoperative seizures. The seizure rate varies between $3 \%$ and $20 \%$ in the literature. ${ }^{1,25,30,34,39}$ It is worth noting that a recent report by Boetto et al. suggested that the rate of intraoperative seizures when using low-frequency bipolar stimulation can be reduced to less than $5 \%{ }^{2}$ Their technique involves preparation of a larger craniotomy to permit visualization of the motor cortex and subsequent stimulation threshold determination through elicitation of electromyography activity and anarthria via stimulation of the motor cortex and ventral premotor cortex, respectively. No electrocorticography was used. They had positive language mapping in all cases with low seizure rates, suggesting that stimulation threshold determination through afterdischarge monitoring may not be necessary. Their results further suggest that the stimulation threshold determined from the motor and ventral premotor cortex is reliable for subsequent language mapping use. Our report differs from this study in important ways. First, our study aimed to assess the role of high-frequency TOF stimulation in asleep patients for motor cortex identification only. The relevance of this technique in language mapping is unclear. Second, our study indicates that high-frequency TOF stimulation is an additional, safe, reliable tool for motor cortex identification, which can be challenging in patients with distorted cortical anatomy and tumors associated with vasogenic edema.

Monopolar high-frequency TOF stimulation was first introduced in 1993 by Taniguchi et al. ${ }^{36}$ Using high-frequency impulses with short interstimulus intervals allowed for an accumulation of excitatory postsynaptic potentials in motor neurons. This method theoretically requires fewer impulses than low-frequency stimulation, which is delivered over longer periods of time. As such, TOF stimulation theoretically delivers a lower charge density and less potential for tissue damage. ${ }^{36}$ The high-frequency stimulation technique, on further testing, has been successfully used for motor and language mapping., ${ }^{4,14,15,24,31}$ Comparing the different stimulation techniques, monopolar highfrequency stimulation has been found to require a lower relative stimulation intensity to achieve a positive MEP. ${ }^{35}$ However, the success of high-frequency stimulation is greatest for mapping of the primary motor cortex and has been found to be less sensitive than bipolar mapping for identifying motor responses in the premotor frontal cortex and supplementary motor areas. ${ }^{15}$ This may be due to the higher density of pyramidal neurons in the primary motor cortex compared to the supplementary motor areas. Importantly, high-frequency stimulation is able to achieve successful mapping with low rates of intraoperative seizure, ranging between $0 \%$ and $3 \% .{ }^{24,37}$

Our case series examined the advantages of high-frequency TOF stimulation delivered using a bipolar electrode, compared with the more traditional low-frequency stimulation. Using this technique, we achieved a significantly higher rate of positive stimulation sites and a low rate of intraoperative seizures. Of the 5 transient neurological deficits that occurred, 2 were in patients who had positive stimulation when using both TOF and low-frequency techniques, and 3 were in patients who had only positive TOF stimulation mapping. Patients who had positive sites with both high- and low-frequency techniques had concordant localization of the motor cortex. All of the motor sites identified by only positive TOF motor localization were in agreement with phase reversal and gross anatomical localization. Since no deficit was permanent or severe and all improved, these were not considered related to inaccurate motor mapping, but rather were deficits secondary to postoperative edema or injury to supplementary motor areas. ${ }^{26}$ In previous studies, monopolar stimulation, with either high- or low-frequency stimulation, had been demonstrated to achieve higher rates of eliciting an MEP while at lower thresholds than bipolar stimulation. ${ }^{35}$ However, monopolar stimulation has a radiant spread that can decrease spatial accuracy, given the typically distant placement of the reference electrode. By using a bipolar wand, where one of the electrodes serves as the reference, our results indicate that high-frequency TOF stimulation can provide spatially accurate motor mapping with extremely low rates of seizures and acceptable postoperative morbidity. It is difficult to confirm whether our higher rate of positive stimulation with the TOF technique was due to a true increase in sensitivity or was actually a false positive. However, given the appropriate correlation of our positive bipolar TOF mapping sites with modalities, such as phase reversal and anatomical landmarks, we favor these sites to be true positives. In addition, although the total number of concordant cases was low for TOF and low-frequency mapping, in those cases there was strong concordance of the positive sites between traditional low-frequency bipolar stimulation and our technique. This suggests that highfrequency TOF stimulation does indicate positive cortical motor sites. Ultimately, this preliminary report points to an additional reliable technique to identify motor cortex.

Our series is limited by the lack of comparison with a monopolar TOF stimulation, potential unconscious bias, lack of blinding, and the small sample size limiting the power of the study. Ideally, our study would have also elucidated the reliability of monopolar TOF mapping of the motor cortex. A future prospective study may further clarify its role. However, some caution may be advisable in a study looking at multiple electrical stimulation techniques given the increased operative time and the increased theo- 
retical risk of seizures. Our higher seizure rate in the lowfrequency group may be confounded by the fact that TOF stimulation was performed prior to low-frequency stimulation. This prior stimulation could theoretically prime the tissue for seizure. However, given that the seizure rate for low-frequency stimulation is consistent with the prior literature, we do not believe this to be the case. In addition, we rarely exceeded $12 \mathrm{~mA}$ of stimulation when using the low-frequency technique out of concern of eliciting seizures at higher amplitudes. We felt this was reasonable given the consistent concordance between our phase reversal and TOF mapping results. That said, it is likely that higher-stimulation amplitudes using the low-frequency technique would have elicited MEPs. Given that direct cortical stimulation is considered the gold standard in functional mapping, the variable responses between the different techniques suggest an interesting issue in calculating sensitivity or specificity of the cortical stimulation methods. How we discern and define true positives and true negatives requires further consideration and discussion among those in the neurosurgical community. That said, our pilot study does not conclude that high-frequency bipolar TOF stimulation provides superior motor cortex identification. Rather, we believe it is an additional reliable tool for motor mapping, which can be challenging in patients with brain tumors and associated edema. It is important to note that there did not appear to be variability in the identification of the motor cortex when both techniques produced positive results. As such, our technique provides an additional reliable modality that reinforces the crucial role of intraoperative mapping for the determination of safe operative corridors and complete tumor resections. Based on our experience, we believe bipolar TOF stimulation is capable of achieving excellent motor mapping with minimal spread, few afterdischarges or seizures, and low rates of permanent postoperative deficits.

\section{Conclusions}

Using a bipolar wand with high-frequency TOF stimulation, we achieved a significantly higher rate of successful motor mapping, as well as a low rate of intraoperative seizure compared to traditional low-frequency bipolar stimulation. This preliminary study suggests that highfrequency TOF stimulation provides a reliable additional tool for motor cortex identification in asleep patients. Further comparison studies of motor mapping techniques are required, and a true gold standard for calculating sensitivity and specificity should be defined.

\section{References}

1. Berger MS, Kincaid J, Ojemann GA, Lettich E: Brain mapping techniques to maximize resection, safety, and seizure control in children with brain tumors. Neurosurgery 25:786-792, 1989

2. Boetto J, Bertram L, Moulinié G, Herbet G, Moritz-Gasser S, Duffau H: Low rate of intraoperative seizures during awake craniotomy in a prospective cohort with 374 supratentorial brain lesions: electrocorticography is not mandatory. World Neurosurg 84:1838-1844, 2015

3. Branco DM, Coelho TM, Branco BM, Schmidt L, Calcagnotto ME, Portuguez M, et al: Functional variability of the human cortical motor map: electrical stimulation findings in perirolandic epilepsy surgery. J Clin Neurophysiol 20:1725,2003

4. Cedzich C, Taniguchi M, Schäfer S, Schramm J: Somatosensory evoked potential phase reversal and direct motor cortex stimulation during surgery in and around the central region. Neurosurgery 38:962-970, 1996

5. Danks RA, Aglio LS, Gugino LD, Black PM: Craniotomy under local anesthesia and monitored conscious sedation for the resection of tumors involving eloquent cortex. J Neurooncol 49:131-139, 2000

6. De Witt Hamer PC, Robles SG, Zwinderman AH, Duffau $\mathrm{H}$, Berger MS: Impact of intraoperative stimulation brain mapping on glioma surgery outcome: a meta-analysis. J Clin Oncol 30:2559-2565, 2012

7. Duffau H: Lessons from brain mapping in surgery for lowgrade glioma: insights into associations between tumour and brain plasticity. Lancet Neurol 4:476-486, 2005

8. Duffau H, Peggy Gatignol ST, Mandonnet E, Capelle L, Taillandier L: Intraoperative subcortical stimulation mapping of language pathways in a consecutive series of 115 patients with Grade II glioma in the left dominant hemisphere. J Neurosurg 109:461-471, 2008

9. Fandino J, Kollias SS, Wieser HG, Valavanis A, Yonekawa Y: Intraoperative validation of functional magnetic resonance imaging and cortical reorganization patterns in patients with brain tumors involving the primary motor cortex. J Neurosurg 91:238-250, 1999

10. Galloway GM, Nuwer MR, Lopez JR, Zamel KM: Intraoperative Neurophysiologic Monitoring. Cambridge, UK: Cambridge University Press, 2010

11. Haglund MM, Berger MS, Shamseldin M, Lettich E, Ojemann GA: Cortical localization of temporal lobe language sites in patients with gliomas. Neurosurgery 34:567-576, 1994

12. Ille S, Sollmann N, Hauck T, Maurer S, Tanigawa N, Obermueller T, et al: Combined noninvasive language mapping by navigated transcranial magnetic stimulation and functional MRI and its comparison with direct cortical stimulation. J Neurosurg 123:212-225, 2015

13. Keles GE, Lundin DA, Lamborn KR, Chang EF, Ojemann G, Berger MS: Intraoperative subcortical stimulation mapping for hemispherical perirolandic gliomas located within or adjacent to the descending motor pathways: evaluation of morbidity and assessment of functional outcome in 294 patients. J Neurosurg 100:369-375, 2004

14. Kombos T, Suess O, Funk T, Kern BC, Brock M: Intraoperative mapping of the motor cortex during surgery in and around the motor cortex. Acta Neurochir (Wien) 142:263268,2000

15. Kombos T, Suess O, Kern BC, Funk T, Hoell T, Kopetsch O, et al: Comparison between monopolar and bipolar electrical stimulation of the motor cortex. Acta Neurochir (Wien) 141:1295-1301, 1999

16. Lacroix M, Abi-Said D, Fourney DR, Gokaslan ZL, Shi W, DeMonte F, et al: A multivariate analysis of 416 patients with glioblastoma multiforme: prognosis, extent of resection, and survival. J Neurosurg 95:190-198, 2001

17. Li YM, Suki D, Hess K, Sawaya R: The influence of maximum safe resection of glioblastoma on survival in 1229 patients: Can we do better than gross-total resection? J Neurosurg 124:977-988, 2016

18. Lilly JC, Hughes JR, Alvord EC Jr, Galkin TW: Brief, noninjurious electric waveform for stimulation of the brain. Science 121:468-469, 1955

19. Ojemann G, Ojemann J, Lettich E, Berger M: Cortical language localization in left, dominant hemisphere. An electrical stimulation mapping investigation in 117 patients. J Neurosurg 71:316-326, 1989 
20. Oppenlander ME, Wolf AB, Snyder LA, Bina R, Wilson JR, Coons SW, et al: An extent of resection threshold for recurrent glioblastoma and its risk for neurological morbidity. J Neurosurg 120:846-853, 2014

21. Penfield W, Boldrey E: Somatic motor and sensory representation in the cerebral cortex of man as studied by electrical stimulation. Brain 60:389-443, 1937

22. Piallat B, Chabardès S, Devergnas A, Torres N, Allain M, Barrat E, et al: Monophasic but not biphasic pulses induce brain tissue damage during monopolar high-frequency deep brain stimulation. Neurosurgery 64:156-163, 2009

23. Raabe A, Beck J, Schucht P, Seidel K: Continuous dynamic mapping of the corticospinal tract during surgery of motor eloquent brain tumors: evaluation of a new method. J Neurosurg 120:1015-1024, 2014

24. Riva M, Fava E, Gallucci M, Comi A, Casarotti A, Alfiero $\mathrm{T}$, et al: Monopolar high-frequency language mapping: can it help in the surgical management of gliomas? A comparative clinical study. J Neurosurg 124:1479-1489, 2016

25. Romstöck J, Fahlbusch R, Ganslandt O, Nimsky C, Strauss $\mathrm{C}$ : Localisation of the sensorimotor cortex during surgery for brain tumours: feasibility and waveform patterns of somatosensory evoked potentials. J Neurol Neurosurg Psychiatry 72:221-229, 2002

26. Rostomily RC, Berger MS, Ojemann GA, Lettich E: Postoperative deficits and functional recovery following removal of tumors involving the dominant hemisphere supplementary motor area. J Neurosurg 75:62-68, 1991

27. Sanai N, Mirzadeh Z, Berger MS: Functional outcome after language mapping for glioma resection. N Engl J Med 358:18-27, 2008

28. Sanai N, Polley MY, McDermott MW, Parsa AT, Berger MS: An extent of resection threshold for newly diagnosed glioblastomas. J Neurosurg 115:3-8, 2011

29. Sartorius CJ, Berger MS: Rapid termination of intraoperative stimulation-evoked seizures with application of cold Ringer's lactate to the cortex. Technical note. J Neurosurg 88:349351,1998

30. Sartorius CJ, Wright G: Intraoperative brain mapping in a community setting - technical considerations. Surg Neurol 47:380-388, 1997

31. Seidel K, Beck J, Stieglitz L, Schucht P, Raabe A: Lowthreshold monopolar motor mapping for resection of primary motor cortex tumors. Neurosurgery 71 (1 Suppl Operative): $104-115,2012$

32. Southwell DG, Hervey-Jumper SL, Perry DW, Berger MS: Intraoperative mapping during repeat awake craniotomy reveals the functional plasticity of adult cortex. J Neurosurg 124:1460-1469, 2016

33. Stummer W, Reulen HJ, Meinel T, Pichlmeier U, Schumacher W, Tonn JC, et al: Extent of resection and survival in glioblastoma multiforme: identification of and adjustment for bias. Neurosurgery 62:564-576, 2008

34. Szelényi A, Joksimovic B, Seifert V: Intraoperative risk of seizures associated with transient direct cortical stimulation in patients with symptomatic epilepsy. J Clin Neurophysiol 24:39-43, 2007

35. Szelényi A, Senft C, Jardan M, Forster MT, Franz K, Seifert $\mathrm{V}$, et al: Intra-operative subcortical electrical stimulation: a comparison of two methods. Clin Neurophysiol 122:1470 1475,2011

36. Taniguchi M, Cedzich C, Schramm J: Modification of cortical stimulation for motor evoked potentials under general anesthesia: technical description. Neurosurgery 32:219-226, 1993

37. Tate MC, Guo L, McEvoy J, Chang EF: Safety and efficacy of motor mapping utilizing short pulse train direct cortical stimulation. Stereotact Funct Neurosurg 91:379-385, 2013

38. Yingling CD: Intraoperative mapping and monitoring of motor cortex-a new paradigm. US Neurology 7:64-67, 2011

39. Yingling CD, Ojemann S, Dodson B, Harrington MJ, Berger MS: Identification of motor pathways during tumor surgery facilitated by multichannel electromyographic recording. J Neurosurg 91:922-927, 1999

40. Zhu FP, Wu JS, Song YY, Yao CJ, Zhuang DX, Xu G, et al: Clinical application of motor pathway mapping using diffusion tensor imaging tractography and intraoperative direct subcortical stimulation in cerebral glioma surgery: a prospective cohort study. Neurosurgery 71:1170-1184, 2012

\section{Disclosures}

The authors report no conflict of interest concerning the materials or methods used in this study or the findings specified in this paper.

\section{Author Contributions}

Conception and design: Ramakrishna, Bander, Kandula, Karceski. Acquisition of data: all authors. Analysis and interpretation of data: all authors. Drafting the article: Ramakrishna, Bander, Shelkov, Modik, Karceski. Critically revising the article: Ramakrishna, Bander, Shelkov, Kandula, Karceski. Reviewed submitted version of manuscript: Ramakrishna, Bander, Karceski. Approved the final version of the manuscript on behalf of all authors: Ramakrishna. Statistical analysis: Ramakrishna, Bander. Study supervision: Ramakrishna.

\section{Correspondence}

Rohan Ramakrishna: Weill Cornell Medical College, New York, NY.ror9068@med.cornell.edu. 